\title{
The power of a partnership approach: the tripartite relationship between academics, academic skills staff and students
}

Poppy Frances Gibson, Robert Morgan, Andrew Sinclair, Rachael Hartiss, Agnieszka Kosek, Ashley Clark

University of Greenwich, UK

\begin{abstract}
This reflection piece shares the innovative approach to an embedded skills model on an accelerated two-year BA programme. At the University of Greenwich annual teaching and learning conference (SHIFT), in 2020, a collaborative team from the degree course presented a case study on this model. This article explores how, through such partnerships, student success can be promoted and student outcomes can shine. Living and teaching through a pandemic has highlighted the importance of staff and student relationships to ensure success.
\end{abstract}

Keywords: partnership, academic skills, embedded, support, trust, connectivism

\section{Introduction}

The role of all staff in higher education (HE), whether professional services staff or academics and lecturers, should be to promote student success. At the recent University of Greenwich annual teaching and learning conference (SHIFT), in 2020, a team composed of lecturers, academic skills professional staff and students from an innovation accelerated degree, the twoyear BA (Hons) in Primary Education, presented a case study on a partnership model that demonstrates how taking time to communicate between all involved can build a culture of support and, as a result, enhance student outcomes. In a model that originated with a pilot in 2018-19, academic and information literacy skills are integrated in the subject curriculum to support students with their studies and also to enhance their abilities and build lasting confidence through employability and citizenship skills (Gibson et al., 2019). The article will reveal the reflections and experiences of the contributors during the academic year, as summarised at the conference.

\section{Views from academic staff on why this partnership works}

The innovative research of Lave and Wenger (1991) uncovered how the professional workplace was the context in which the process of social participation underpinned the relationship between newcomers and experienced practitioners. Within such a social environment, this integration of individuals occurred where learning involved participation in a 'community of practice'. These authors' description of 'learning' was a process which evolved continuously, becoming defined as a renewed set of relations perceived by the person engaging with the 
learning. Therefore, learning was centred in the relationships between people, where knowledge was shared.

From an academic point of view, the relationship established between an academic skills team and students is one that erases assumption, promotes transparency and enhances academic outcomes. Within HE, it should be assumed neither that students know how to write for an academic assignment nor that they see their academic tutor as a partner in this process. So, a relationship between tutor, student and academic skills tutor becomes a community of practice, wherein each member has confidence in the others and so all can learn, with consequent enhancement of academic outcomes for students: staff come to understand how students learn during a two-year accelerated degree and therefore how to meet their needs by developing in them appropriate skills (Morgan, 2019) ${ }^{1}$; students acquire the necessary skills and learn how to apply them. From a theoretical perspective, this illustrates the concept of "connectivism" a "knowledge of a connection within a network" (Downes, 2004, in Bell, 2009). Connectivism is partly predicated on the notion of "nurturing and maintaining connections needed to facilitate continual learning" (Siemens, 2004, in Bell, 2009).

This partnership works because of investment in programme reform, collaboration and trust. In our programme, we developed communication with the academic skills team so they could visit students during targeted modules. They were informed of the students' assignments so their support could be specific; for example, giving possible structural advice for the assignment question. The members of this team could acquire, in 'real time', a sense of the academic needs of current students in order to plan future provision. In terms of collaboration, reform of the programme brought benefits: it enabled - during module teaching time with its more efficient skills-tutor-to-student ratio - better provision of support for students, while - in response to a popular complaint - ending the time-wasteful individual student appointments' system opened up opportunities for timetabled support sessions for all interested students. Trust is a key word for this partnership, this community. Each of us responds favourably to trust: tutors addressing a student's academic needs with academic skills development will place their trust in her; a student will trust his tutors to help him improve his academic performance; tutors show trust in the efficacy of academic skills as part of teaching programmes. This is the evidence from student surveys showing the effects of the partnership:

GSS 2020

"Staff genuinely want you to succeed"

"The lecturers are very welcoming and make a point of being available and providing additional support and reading even if not asked."

\footnotetext{
1 This is a document entitled 'Preparation for written assignments' (Morgan, 2019) that is emailed to all students in QTS and non QTS programmes designed to help them with academic writing, and in particular structuring of academic assignments. The document refers to three zones that students follow in the development of an assignment: $\mathrm{A}$ - reading, $\mathrm{B}$ - writing the first draft and $\mathrm{C}$ - drafting and editing. Copies may be received from Robert Morgan r.a.morgan@gre.ac.uk
} 
“They clearly take an interest in the students' wellbeing and performance and take steps to help."

Module ACAD 1340

"The lectures and seminars are engaging and are very interesting. The delivery is brilliant and stimulates learning. $B^{\star}$ and $P^{*}$ are two amazing lecturers. The guidance given to ensure we understand our assessment and is on track with everything is phenomenal. I enjoyed this module and I think it is one of the best modules on the programme along with Personalised learning $1 . .$. they are very two supportive lecturers who are very organised and challenge us to learn and do our best."

\section{Views from academic skills staff on why this partnership works}

The benefits of embedding academic skills in subject programmes have been acknowledged for some time (Wingate and Andon, 2011; Wingat et al., 2006). Despite this, there is still a tendency in some quarters to view academic skills as a quick-fix solution, rather in the manner of a box-ticking exercise, to what is a much more complex problem. It is naïve to assume that students enter HE with the requisite skills to cope with the demands of independent learning. Unfortunately, the 'bolt-on' approach to academic skills provision tends to focus on generic skills without the necessary context, meaning that students are trying to learn in a vacuum. This denies them opportunities for experiential learning, problem-solving and reflection, all of which are essential for the development of independent learning skills (Kolb, 1984).

What this partnership approach has allowed us to do has not only been to embed academic skills in an academic programme, but also to deliver these in collaboration with the academic teaching staff. Regular contact means we have been able to develop a good rapport with both the staff and students, allowing for a more individualised approach to learning, strengthened by good working relationships. This strategy breaks down barriers and has created a refreshing egalitarianism: we work together rather than in isolation. The academic skills interventions are tailored to the demands of the assignments, so that the skills can be applied in a context that is both specific and meaningful. The assignments have formative elements that allow students to receive feedback, to reflect upon that and then to act upon it, as a preliminary step to tackling the summative assessment. In this environment, the students develop greater autonomy and responsibility for their own academic development.

As for the type of intervention, we work on specific interventions delivered with subject tutors in a classroom context; we offer drop-in sessions, either individual or group, aimed specifically at this cohort. Students are also able to book one-to-one tutorials with an academic skills tutor or a librarian, sessions which are available to all students. We find that, on account of the greater classroom contact, many students avail themselves of these appointments and then, instead of perceiving academic skills in a remedial capacity, they see them - quite correctly - as support tools to maximise their full potential. In a Mentimeter survey run with the pilot cohort, all students who participated in the survey either agreed or strongly agreed that the academic support they had received had helped them to progress. There are challenges in relation to 
resourcing, since the academic support team is a very small team, catering for students across three campuses. Nevertheless, the success of the partnership approach indicates that this is the way forward.

\section{Views from students on why this partnership works}

Many students, when commencing HE, lack confidence in their ability to cope with the academic demands and feel unprepared for study (Gibson et al., 2019). Embedded in the structure of the two-year accelerated BA (Hons) in Primary Education is a culture of effective communication between academic staff, professional support staff and the student. Through continuous, multifaceted support, students are afforded an opportunity to enhance their work at an accelerated rate. As a result, their academic skills, self-esteem and communication all improve, leading to academic success within the programme. Students are effectively scaffolded as they progress through the levels of study, working towards independence in their academic work. As students enter the degree programme from a variety of circumstances and backgrounds, the individually tailored approach is beneficial to their development.

From a student perspective, having parallel support from academic and professional support staff provides a multi-disciplinary approach to learning. Within the first term of the degree programme, the initial contact with the academic skills team, as part of a co-taught seminar, lays the foundations of academic thought. In the seminar, students are taught to source material effectively and thus to benefit their academic work. Students are also guided on how to approach critical reading and filtering, to analyse and synthesise the information. To make such provision early provides students with a sense of the kind of support for adequately developing their academic skills that they may continue to expect: their knowledge gap will, they realise, be quickly closed and they will feel much more confident about moving forward through the levels of study.

In the second year of study, there is a continuation of a multi-disciplinary approach, based on effective communication between all parties (figure1). The system of learning implemented is so structured that students are on an equal footing with both academic and professional staff. Personalised teaching informed by student voices (Gibson, 2020; Gibson et al., 2019) narrows the learning gap, stimulates greater student engagement and develops positive studenteducator relationships. Throughout the programme, access to drop-in viva-practice sessions with the academic skills team develops an understanding of assessment-based feedback. In turn, this aids the development of critical thinking, writing and reflective skills. The variety of opportunities (e.g., presentations) offered by lecturers positively influences the development of student's intra-personal skills - self-efficacy, motivation and metacognition - vital for selfdiscovery, academic success and the choice of a self-fulfilling career path. 


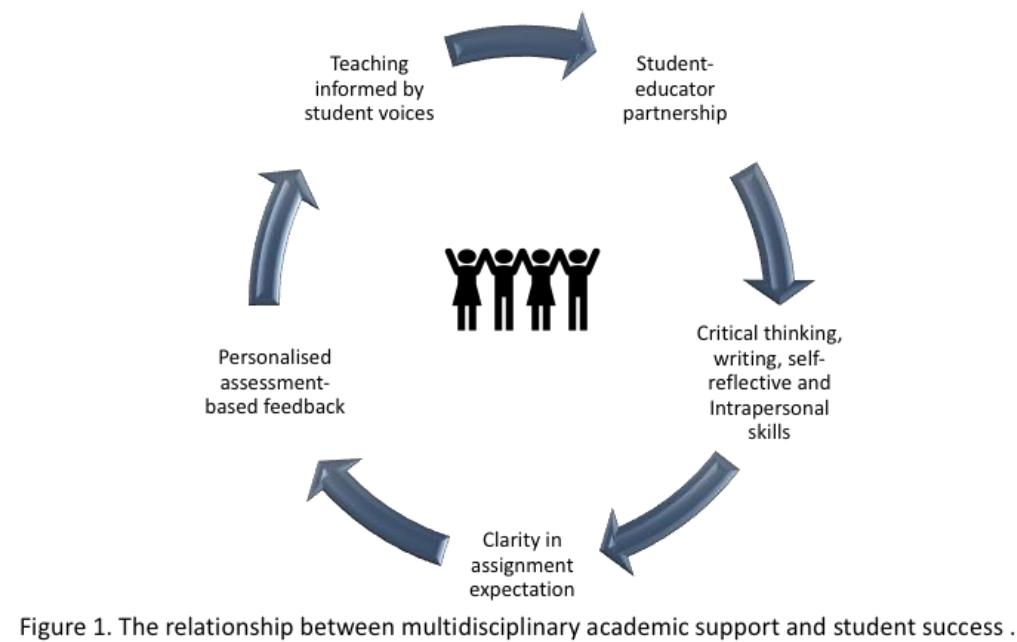

\section{Conclusion}

This short reflection has highlighted that - whether we are in a classroom together or having to teach and learn remotely owing to a pandemic - what is important is the union of staff in supporting our students. Where academic skills are needed at the very core and foundation of successful study, having a partnership between lecturers and the academic skills team can offer to students a consistent and coherent provision; this partnership ensures that all involved are giving the same information to avoid student confusion.

\section{Reference list}

Bell, F. (2009) 'Connectivism: a network theory for teaching and learning in a connected world.' Available at: http://usir.salford.ac.uk/id/eprint/2569/1/ConnectivismEdDev.pdf (Accessed: 9 March 2021).

Gibson, P. (2020) 'Letting students' voices be heard: building effective learning relationships and increasing outcomes on the 2-year accelerated BA (Hons) in Primary Education.' Greenwich Learning and Teaching. Available at: https://blogs.gre.ac.uk/glt/2020/02/17/lettingstudents-voices-be-heard-primary-education/ (Accessed: 17th February 2020).

Gibson, P., Perera, S., Morgan, R. and Kerr, B. (2019) 'Creating conditions for student success on a two-year accelerated degree.' Compass: Journal of Learning and Teaching, 12(1). Available at: https://doi.org/10.21100/compass.v12i1.944 (Accessed: 12 January 2021).

Kolb, D. (1984) Experiential Learning. Englewood Cliffs, New Jersey: Prentice Hall. ISBN: 9780132952613

Lave, J. and Wenger, E. (1991) Situated learning: Legitimate peripheral participation. Cambridge, UK: Cambridge University Press. ISBN: 9780511815355 
Wingate, U., Andon, N. and Cogo, A. (2011) 'Embedding academic writing instruction into subject teaching: A case study.' Active Learning in Higher Education, 12(1), 69-81. Available at: https://journals.sagepub.com/doi/10.1177/1469787410387814 (Accessed: 12 January 2021).

Wingate, U. (2006) 'Doing away with study skills.' Teaching in Higher Education, 11(4), 457469. Available at: https://www.tandfonline.com/doi/abs/10.1080/13562510600874268 (Accessed: 12 January 2021). 